\title{
Atividade isoenzimática em plantas de trigo infectadas com o vírus SBWMV
}

\author{
Rocheli de Souza ${ }^{(1)}$, Jurema Schons ${ }^{(1)}$, Sandra Patussi Brammer(2), Ariano Moraes Prestes ${ }^{(2)}$, \\ Pedro Luiz Scheeren ${ }^{(2)}$, Marcio Só e Silva(2) e Leo de Jesus Antunes Del Duca(2)
}

\begin{abstract}
(1)Universidade de Passo Fundo, Fac. de Agronomia e Medicina Veterinária, BR 285, Km 171, Caixa Postal 611, CEP $99001-970$ Passo Fundo, RS. E-mail: rochelisouza@yahoo.com.br, schons@upf.br (2)Embrapa Trigo, BR 285, Km 174, Caixa Postal 451, CEP 99001-970 Passo Fundo, RS. E-mail: sandra@cnpt.embrapa.br, prestes@cnpt.embrapa.br, scheeren@cnpt.embrapa.br, soesilva@cnpt.embrapa.br, delduca@cnpt.embrapa.br
\end{abstract}

\begin{abstract}
Resumo - O objetivo deste trabalho foi elucidar a atividade e a expressão isoenzimática das esterases, das peroxidases e das aspartato aminotransferases em função da infecção de plantas de trigo pelo Soil-borne wheat mosaic virus (SBWMV). Foram analisadas, aos 45 dias após a emergência, quatro cultivares e uma linhagem de trigo, com diferentes níveis de resistência ao SBWMV: BRS Guabiju, BRS 194, BRS 179, BR 23 e PF 980524. De modo geral, ocorreram diferenças qualitativas e quantitativas intra e interpopulacional, quando comparadas plantas assintomáticas e sintomáticas ao SBWMV. Para o sistema esterase, nove padrões de bandas foram determinados e para peroxidase e aspartato aminotransferase foram detectados três padrões de bandas, para ambas as condições. Padrões eletroforéticos foram observados para plantas infectadas, quando comparadas com as não infectadas, destacando-se a atividade da esterase, o que permitiu identificar com maior precisão o estado metabólico e diferenciado das células.
\end{abstract}

Termos para indexação: Triticum aestivum, variabilidade genética, esterase, peroxidase, aspartato aminotransferase.

\section{Isoenzymatic activity in wheat plants infected by virus SBWMV}

\begin{abstract}
The aim of this work was to elucidate the effect of the Soil-borne wheat mosaic virus (SBWMV) on the activity and on the isoenzymatic expression of esterases, peroxidases, and aspartate aminotranferases in wheat plants. Biochemical analyses were carried out for four cultivars and one line of wheat, 45 days after emergence with different levels of resistance to SBWMV: BRS Guabiju, BRS 194, BRS 179, BR 23 and PF 980524. In general, intra and interpopulation differences in quality and quantity were detected, when comparing plants with and without symptoms of SBWMV. Nine band patterns were determined in both situations for esterase. To peroxidase and aspartato aminotransferase, three band patterns were detected for both conditions. Eletrophoretic patterns of SBWMV infected plants were observed, when compared with noninfected ones, notably for esterase, which provides a more precise identification of cell metabolic condition.
\end{abstract}

Index terms: Triticum aestivum, genetic variability, esterase, peroxidase, aspartate aminotransferase.

\section{Introdução}

O mosaico do trigo (Soil-borne wheat mosaic virus - SBWMV) é uma das mais preocupantes viroses da cultura de trigo no Brasil. Ocorre, principalmente, no planalto do Rio Grande do Sul e no Sul do Paraná e acarreta danos consideráveis ao rendimento de grãos; é o mais conhecido dos Furovirus e caracteriza-se por ser transmitido pelo fungo do solo Polymyxa graminis L., um parasita obrigatório comum de raízes de gramíneas (Chen et al., 1998).

Os sintomas mais característicos consistem na inibição do desenvolvimento da planta, brotamento excessivo, que resulta em aparência enrosetada, e a mistura de cores verde e amarela nas folhas, com aspecto de mosaico, característica que designa o nome da virose (McKinney et al., 1923).

No melhoramento genético, o uso de marcadores morfológicos nem sempre é eficiente, pois estes variam conforme as condições ambientais e não permitem a detecção de grande número de locos, uma vez que não cobrem todo o genoma, bem como seu controle genético pode afetar ou ser afetado por genes que controlam outros caracteres.

Técnicas bioquímicas e moleculares, baseadas na análise de polimorfismo de enzimas e de fragmentos de DNA, possibilitam a rápida detecção de marcadores 
genéticos no estudo de aspectos básicos de genética vegetal, são também ferramenta de apoio aos programas de melhoramento, pois possibilitam, de forma mais rápida e precisa, a avaliação e a identificação antecipada de genótipos resistentes e suscetíveis, antes que a doença ocorra sobre a cultura do trigo (Brammer, 2000).

A indução e a expressão de proteínas, atribuídas à infecção de tecidos de plantas causada por vírus, têm sido registradas para várias espécies (Burdon \& Marshall, 1983). De acordo com esses autores, estudos isoenzimáticos, em casos de estresses bióticos ou abióticos, estão relacionados ao entendimento das mudanças metabólicas e mecanismos de defesa desencadeados pelas plantas.

Uma técnica bioquímica amplamente utilizada é o sistema de eletroforese com isoenzimas, que são definidas como diferentes formas moleculares de uma mesma enzima, que ocorrem num mesmo organismo, com afinidade por um mesmo substrato. O resultado da presença de mais de um gene, codificado para cada uma das enzimas, indica que são controladas geneticamente por um ou vários genes, situados num mesmo loco ou diferentes locos, respectivamente. A variação em certas isoenzimas pode ser importante na capacidade das plantas de sobreviverem em ambientes diversos. Assim, estresses que afetam o metabolismo da planta como nutrição, temperatura e infecções por patógenos influenciam a intensidade da atividade enzimática e podem refletir no surgimento de formas moleculares múltiplas, por ativação de genes (Gottlieb, 1982).

A eletroforese de isoenzimas fornece um meio de avaliação da variação genética. Existem, atualmente, muitas técnicas que ampliam o poder de detecção no nível de DNA, pois as isoenzimas exibem um potencial enorme para a aplicação em genética de plantas (Ferreira \& Grattapaglia, 1998). Apesar de as técnicas de isoenzimas detectarem apenas os eventos mutacionais, que alteram a carga elétrica das proteínas em regiões codificadoras, e de um número limitado de genes que se expressam em enzimas dependentes de estádio de desenvolvimento da espécie, tais técnicas são consideradas de custo baixo e de ótimos resultados. Outra vantagem é que os polimorfismos enzimáticos estão mais próximos da expressão fenotípica final do que os polimorfismos de DNA, por serem um produto intermediário da expressão do gene (Torggler et al., 1995).

A informação básica ao se visualizar os dados enzimáticos é a de que diferenças na mobilidade de isoenzimas, em um campo elétrico, são resultantes das seqüências de DNA que codificam essas enzimas. Em virtude das propriedades catalíticas das enzimas, as isoenzimas, especialmente, podem refletir o estado metabólico e diferenciado das células (Scandalios, 1979).
A expressão das isoenzimas é codominante, isto quer dizer que, em um indivíduo diplóide, ambos os alelos de um loco são expressos e visualizados (Ferreira \& Grattapaglia, 1998).

O objetivo do presente trabalho foi estudar diferenças na atividade eletroforética das isoenzimas esterase, peroxidase e aspartato aminotransferases, de plantas de trigo sintomáticas e assintomáticas ao vírus SBWMV.

\section{Material e Métodos}

Os genótipos de trigo foram cultivados na área experimental, e as análises bioquímicas foram realizadas no Laboratório de Biotecnologia Vegetal da Embrapa Trigo, em Passo Fundo, RS.

Foram utilizadas 4 cultivares e uma linhagem de trigo, com diferentes níveis de resistência ao SBWMV: BRS Guabiju, moderadamente resistente; BRS 194, resistente; BRS 179, moderadamente suscetível; BR 23, suscetível; PF 980524, altamente suscetível (Reunião..., 2003).

O delineamento experimental foi o de blocos ao acaso, com duas repetições. Cada parcela foi constituída de 5 linhas de $5 \mathrm{~m}$ de comprimento, com 0,2 m entre as linhas. A densidade de semeadura foi de 330 sementes viáveis $\mathrm{m}^{-2}$ e a adubação de base $450 \mathrm{~kg} \mathrm{ha}^{-1}$ da fórmula NPK 5-25-25. A adubação de cobertura foi de $45 \mathrm{~kg} \mathrm{ha}^{-1}$ de $\mathrm{N}$, na forma de uréia, aplicada trinta dias após o plantio. Os tratamentos fitossanitários foram feitos de acordo com as recomendações técnicas oficiais para a cultura do trigo.

Todos os genótipos apresentavam-se no mesmo estádio de desenvolvimento e permaneceram na mesma área experimental. Os fungos foram inoculados naturalmente nas plântulas, utilizando-se solo infestado com Polymyxa graminis, vetor do SBWMV; 45 dias após a emergência das plantas, foram coletados, separadamente, um ápice foliar com $3 \mathrm{~cm}$ de comprimento, para cada uma das 6 plantas assintomáticas e 6 sintomáticas, que se encontravam na fase final de perfilhamento, para todos os genótipos em estudo. A coleta foi realizada no mesmo dia para todos os genótipos, e logo foi feito o corte da parte apical. Os cortes de cada genótipo foram identificados e armazenados a $-20^{\circ} \mathrm{C}$ até o momento do uso.

O tecido foliar foi homogeneizado, manualmente, com auxílio de um bastão de vidro com ponta esmerilhada, com o tampão Fosfato $0,1 \mathrm{M} \mathrm{pH}$ 7, em placas de acrílico mantidas sobre gelo. Sobre o homogeneizado foi colocado, inicialmente, um disco de papel filtro autoclavado, seguido da imersão dos 
papéis de aplicação das amostras (Whatman 3MM, com dimensões de 4 mm x 1 mm).

Os géis foram preparados para a concentração de $7 \%$ de AA/BIS, em solução tampão fosfato $0,1 \mathrm{M} \mathrm{pH} 7$ e, para a polimerização, foram adicionados $100 \mu \mathrm{L}$ de $\mathrm{N}, \mathrm{N}, \mathrm{N}^{\prime}, \mathrm{N}$ ', tetrametiletilenodiamina (TEMED), e $1.000 \mu \mathrm{L}$ de persulfato de amônio a $10 \%$. O sistema das esterases (EST, EC 3.1.1) e peroxidases (PO, EC 1.11.1.7) foram baseados em Scandalios (1969), e o das aspartato aminotransferases (AAT, EC 2.6.1.1) em Brown \& Weir (1983), tanto para o preparo dos géis como para as revelações. A polimerização do gel foi realizada em temperatura ambiente, por cerca de $20 \mathrm{~min}$; foram, então, transferidos para balcão refrigerado a $4^{\circ} \mathrm{C}$, onde permaneceram até sua utilização.

Após a aplicação das amostras, os géis foram migrados em cubas eletroforéticas horizontais, à temperatura constante de $4^{\circ} \mathrm{C}$. A linha do ponto de aplicação das amostras foi mantida a uma distância de $1 \mathrm{~cm}$ da ponte catódica. A distância entre a ponte catódica e anódica foi de $12 \mathrm{~cm}$, e a intensidade do campo elétrico de $10 \mathrm{~V} \mathrm{~cm}^{-1}$. A migração das amostras foi interrompida, quando a linha de frente, marcada com azul de bromofenol, atingiu $9 \mathrm{~cm}$.

A revelação dos géis ocorreu de acordo com cada sistema isoenzimático empregado. Os sistemas das esterases e peroxidases foram baseados em Scandalios (1969), e o das aspartato aminotransferases em Brown \& Weir (1983).

As análises das isoenzimas foram baseadas na representação da migração absoluta (MA) em papel milimetrado, e foram anotadas a intensidade de coloração de cada banda e as distâncias migradas pelas mesmas, a partir do ponto de aplicação, em centímetros, com precisão de $0,5 \mathrm{~mm}$. A partir desse esquema, foi calculada a migração relativa (MR) de cada banda, em relação à linha de frente $(M R=1)$. A MR indica a relação entre a distância migrada pela banda em questão, e a distância migrada pela linha de frente.

Para a representação dos padrões eletroforéticos no zimograma, procedeu-se do seguinte modo: quando uma ou mais plantas demonstraram exatamente o mesmo padrão, foi usada uma única representação, que indicava o número de plantas; quando as plantas demonstraram variação, seja de bandas diferentes, ou de presença/ausência de bandas, foi usado o mesmo padrão respectivo de cada planta (Brammer, 1993).

\section{Resultados e Discussão}

Nove padrões de bandas foram determinados para as esterases (EST), tanto para plantas assintomáticas do mosaico, como para aquelas sintomáticas, dentro de todos os genótipos utilizados (Figura 1). De modo geral, ocorreram diferenças qualitativas (presença e ausência de banda), e quantitativas (intensidade da banda) intra e interpopulacional das isoesterases, quando comparadas as duas condições.

Na cultivar BRS Guabiju houve poucas diferenças entre plantas assintomáticas e sintomáticas da virose, exceto para uma planta que, no caso da primeira condição, possui unicamente a MR 0,60, e para a MR 0,56 as bandas foram mais intensas do que quando comparada com a segunda condição. Nas plantas com vírus, as MRs 0,53 e 0,50 apresentaram atividade maior em relação às plantas assintomáticas.

A cultivar BR 23 apresentou maiores diferenças qualitativas e quantitativas na condição assintomática. Outro aspecto observado foi o de diferenças internas entre as plantas: nas assintomáticas houve a presença da MR 0,30, não observada nas sintomáticas. Os resultados observados nessa cultivar indicaram diminuição da atividade da isoenzima nas plantas sintomáticas, principalmente nas MRs 0,27 e 0,25. O contrário foi observado com o padrão eletroforético da cultivar BRS 179, em que houve uma tendência de maior intensidade isoenzimática nas plantas sintomáticas (MR 0,51; 0,53 e 0,56 ), tendo revelado um aumento na atividade da isoenzima.

Para a cultivar BRS 194 com vírus, não ocorreu ativação enzimática nas MRs 0,$21 ; 0,25 ; 0,27$ e 0,30, quando comparadas com as plantas assintomáticas, o que demonstra o efeito do vírus sobre a planta e indica o uso das esterases como ferramenta para monitoramento e seleção assistida.

Para a linhagem PF 980524, o número de bandas nas plantas assintomáticas foi de três a oito, enquanto que nas plantas sintomáticas as bandas variaram de 2 a 5, o que indica a diminuição do número de bandas nessa linhagem, principalmente quando atacada pelo vírus. Outro fato está na ocorrência da presença de banda com MRs 0,51 e 0,60 somente nas plantas assintomáticas. As demais MRs nas plantas assintomáticas, de modo geral, foram mais intensas do que as sintomáticas.

Pascholati et al. (1993) relataram que um dos sistemas comumente utilizados é o da esterase, que é polimórfica e de fácil detecção, além de estar relacionada com a patogenicidade. Em revisão sobre o trigo, Hart (1983) relatou que isoesterases foram intensivamente investigadas e vários trabalhos realizados por diversas instituições, o que permitiu pesquisar a localização cromossômica dessa isoforma em vários tecidos e em vários estádios de desenvolvimento. 
Comparando-se os resultados obtidos no presente trabalho, verificou-se que resultados diferentes foram encontrados por Wagih (1991), que estudou a atividade de esterase em feijão (Phaseolus vulgaris L.), após a infecção com Peanut mottle virus - PMV. Esse autor observou cinco isoesterases de MRs 0,08; 0,19; 0,25; 0,30 e 0,33 , que foram determinadas em folhas sadias não infectadas com PMV. Foi verificado que nem a abrasão nem a infecção viral com PMV resultaram em modificações qualitativas e quantitativas em padrões de isoesterases.

Em outro trabalho, o estudo e caracterização isoenzimática de isolados de Pyrenophora chaetomioides, principal agente causal da mancha foliar da aveia (Avena sativa L.), revelaram a associação de uma elevada atividade enzimática de
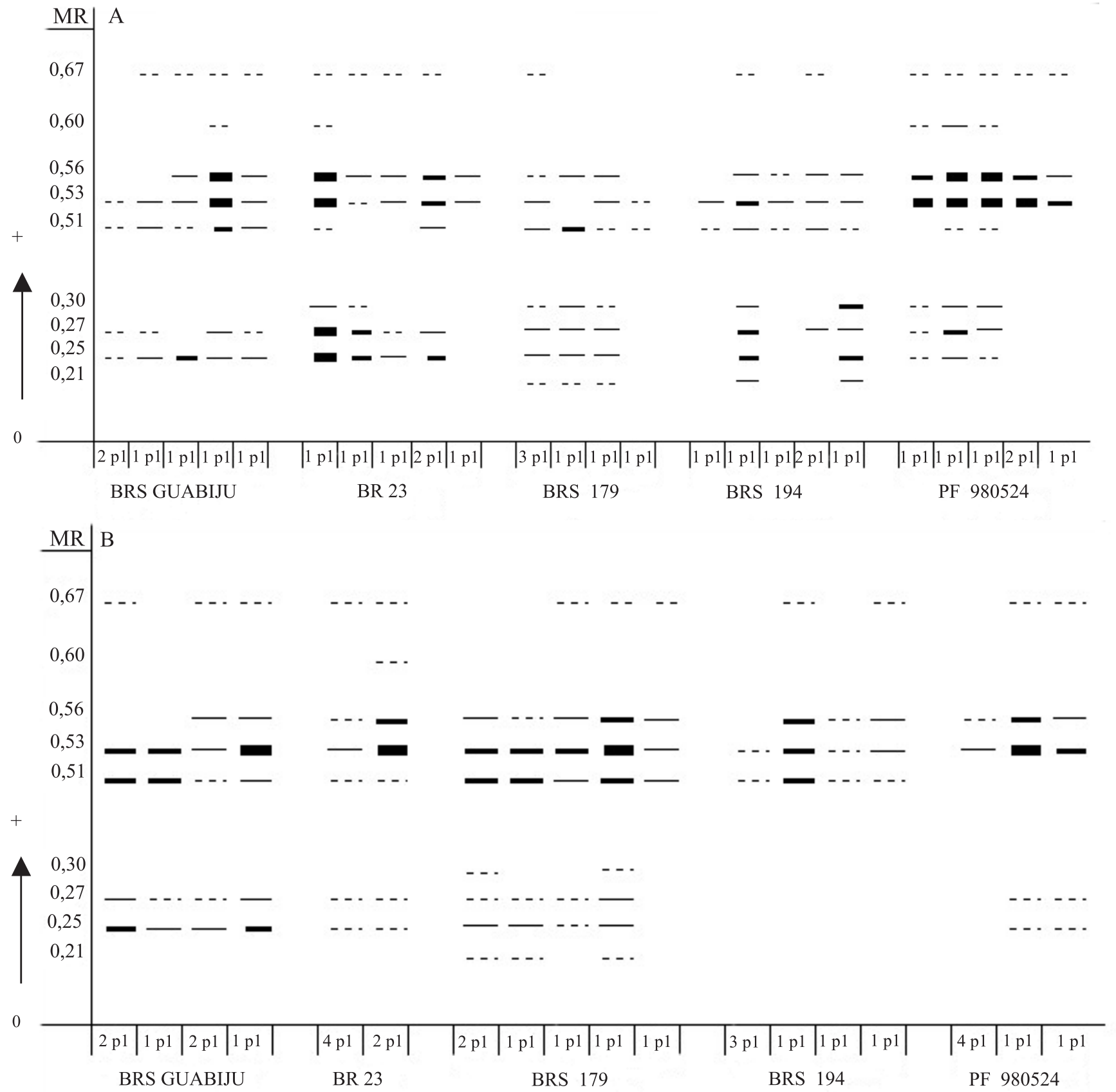

Figura 1. Zimograma de esterases de folhas de quatro cultivares e uma linhagem de trigo assintomáticas (A) e sintomáticas (B) ao SBWMV, mostrando atividade forte (-), média (-), fraca (-) e fraquíssima (---); pl: número de plantas. 
esterase com os isolados mais virulentos (Bocchese et al., 2003).

Silva et al. (2000) observaram uma diminuição no número e intensidade de bandas de esterases em sementes de milho, infectadas com Aspergillus flavus e Penicillium spp., assim como em sementes tratadas com fungicidas.

Para o sistema peroxidase (PO) observou-se diferenças intra e interpopulacional. Foram detectados três padrões de bandas para ambas as condições (assintomáticas e sintomáticas), cujas MRs variaram de 0,07 a 0,12 (Figura 2). Também foram observadas diferenças qualitativas e quantitativas nas plantas assintomáticas e sintomáticas. Nos genótipos suscetíveis ao SBWMV (BR 23 e PF 980524), as bandas eletroforéticas apresentaram-se com menor intensidade nas plantas assintomáticas.

Nas cultivares BRS 194, resistente, e BRS Guabiju, moderadamente resistente ao SBWMV, não foram detectadas diferenças de intensidade nas bandas entre plantas assintomáticas e sintomáticas, porém, para o BRS 194 observou-se a presença em quatro amostras de MR 0,07, não detectada na condição sintomática.

Resultados semelhantes aos obtidos no presente trabalho foram encontrados por Ye et al. (1990), ao inocular o Tobacco mosaic virus (TMV) em folhas de tabaco,
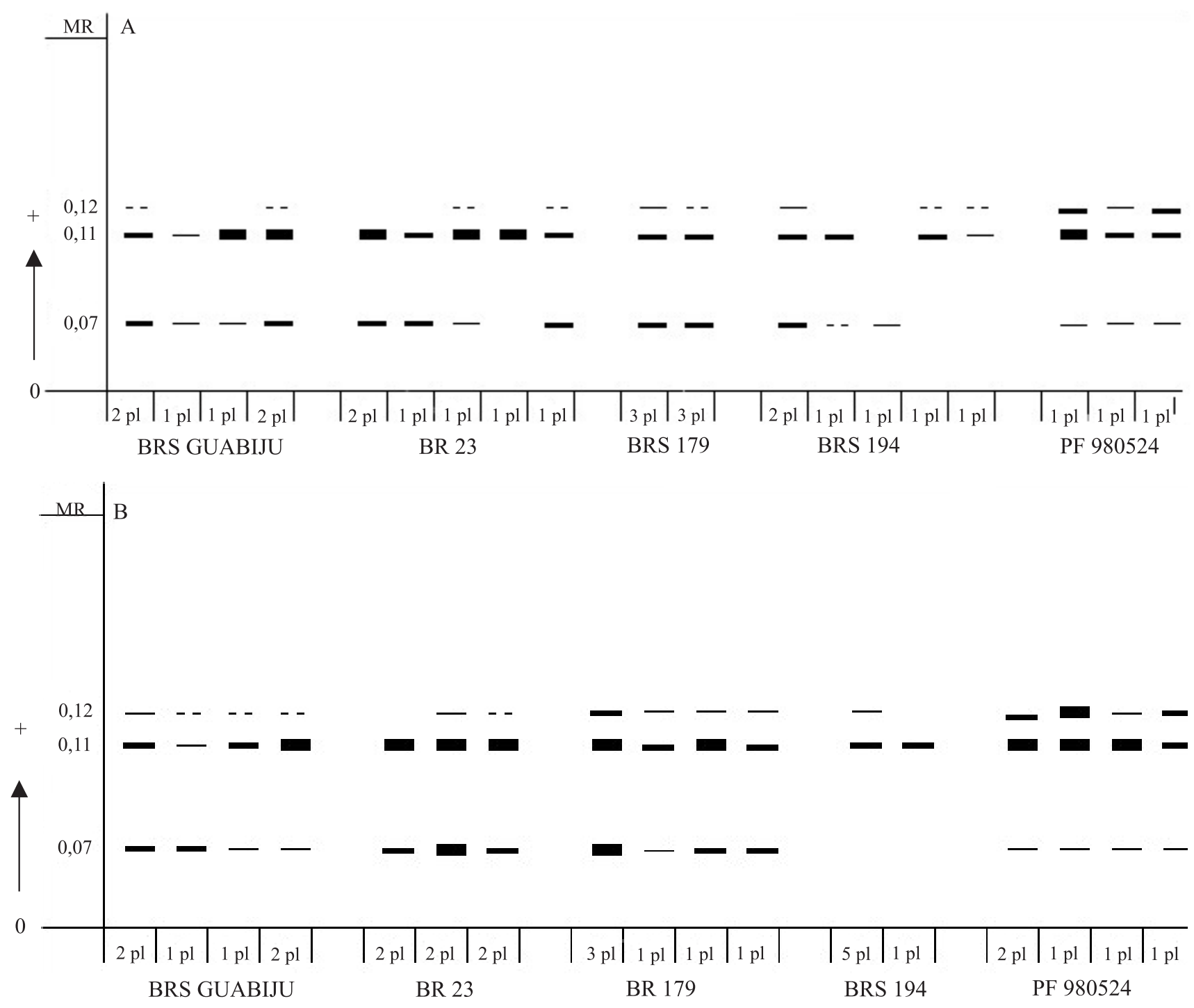

Figura 2. Zimograma de peroxidases de folhas de quatro cultivares e uma linhagem de trigo assintomáticas (A) e sintomáticas (B) ao SBWMV, mostrando atividade forte ( - ), média (-), fraca (-) e fraquíssima (---); pl: número de plantas. 
o que provocou um aumento sistêmico na atividade das isoperoxidases e desencadeou os mecanismos de indução de resistência ao TMV.

Visedo et al. (1991) também observaram que alterações, em larga escala, têm sido encontradas nos perfis das isoperoxidases em folhas de Nicotiana clevelandii com inoculação de Plum pox virus (PPV), especialmente em lesões locais resultantes da infecção viral.

Venere (1980) e Mellon (1991) relataram que alterações nos níveis de peroxidases e distribuição de isoformas são conhecidas por acompanhar grandes processos das plantas (mecanismos de defesa dos hospedeiros a patógenos, como lignificação e suberização) e que, em pequeno número de sistemas de plantas, inclusive fumo, batata, nabo e cevada, essas isoformas têm sido caracterizadas e purificadas.

Em relação às isoenzimas aspartato aminotransferases (AAT), três padrões de bandas, MRs de 0,62 a 0,76 , foram determinados para as duas condições na maioria dos genótipos, com exceção de BRS Guabiju e de BR 23, em que apenas dois padrões de bandas foram identificados (Figura 3), e que para o segundo, não houve diferenças
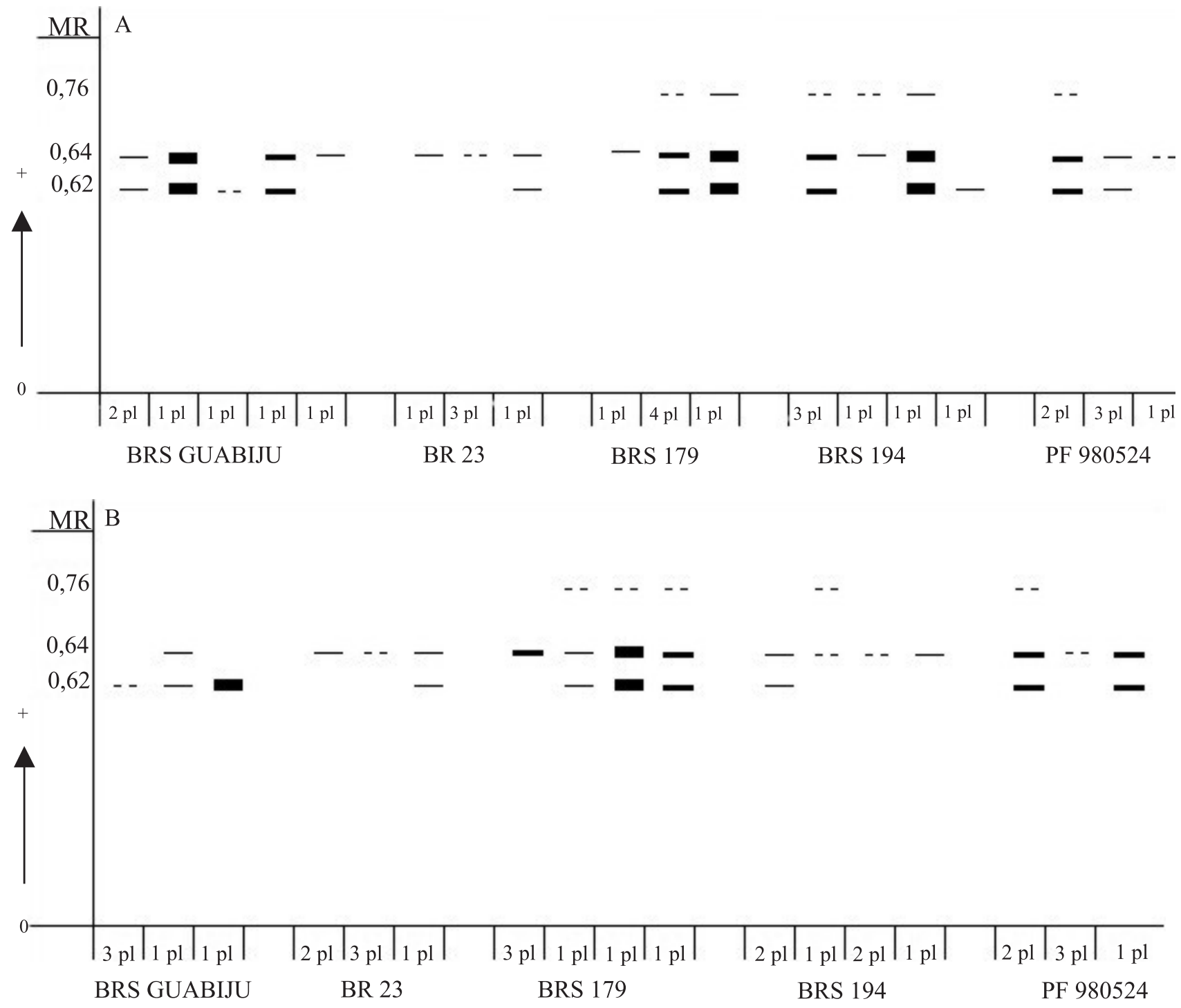

Figura 3. Zimograma de aspartato aminotransferases de folhas de quatro cultivares e uma linhagem de trigo assintomáticas (A) e sintomáticas (B) ao SBWMV, mostrando atividade forte (-), média (-), fraca (-) e fraquíssima (---); pl: número de plantas. 
qualitativas entre as plantas assintomáticas e sintomáticas. Do mesmo modo, BRS 179 e PF 980524 também não apresentaram diferenças marcantes entre as plantas assintomáticas e sintomáticas. Na cultivar BRS 194 foi detectada a presença de bandas com maior intensidade, principalmente para as MRs 0,64 e 0,62 nas amostras assintomáticas da virose.

Considerando a ativação ou não de isoenzimas frente a patógenos, Silva et al. (2000) estudaram a interferência de fungos Aspergillus flavus, Fusarium moniliforme e Penicillium spp. sobre padrões eletroforéticos dessa isoforma, em sementes de milho. Esses autores concluíram que a infecção de sementes com os fungos promoveu diferenças nas expressões das aspartato aminotransferases, e que houve diminuição da intensidade do número de bandas, em virtude da presença desses patógenos.

\section{Conclusões}

1. As atividades e expressões isoenzimáticas das esterases, peroxidases e aspartato aminotransferases proporcionam estudos intra e interespecíficos das interações patógeno-hospedeiro.

2. Destacam-se diferentes padrões eletroforéticos e atividades isoenzimáticas das esterases, peroxidases e aspartato aminotrasferases para plantas de trigo sintomáticas, quando comparadas às plantas assintomáticas da virose causada pelo SBWMV.

3. A esterase, entre as isoenzimas analisadas, e por apresentar maior polimorfismo, permite identificar com maior precisão o estado metabólico e diferenciado das células, em relação à infecção com o SBWMV.

\section{Referências}

BOCCHESE, C.A.C.; MARTINELLI, J.A.; MATSUMURA, A.T.S.; FEDERIZZI, L.C.; PRESTES, A.M. Virulência, atividade enzimática e padrões de isoesterases de isolados de Pyrenophora chaetomioides, agente etiológico da mancha de grãos e folhas de aveia. Fitopatologia Brasileira, v.28, p.11-16, 2003.

BRAMMER, S.P. Mapeamento de genes de resistência parcial à ferrugem da folha do trigo em cultivares brasileiras de trigo (Triticum aestivum L.). 2000. 215p. Tese (Doutorado) - Universidade Federal do Rio Grande do Sul, Porto Alegre.

BRAMMER, S.P. Variabilidade isoenzimática em populações naturais de Hordeum stenostachys (Poaceae). 1993. 209p.
Dissertação (Mestrado) - Universidade Federal do Rio Grande do Sul, Porto Alegre.

BROWN, A.H.D.; WEIR, B.S. Measuring genetics variability in plant populations. In: TANKSLEY, S.D.; ORTON, T.J. (Ed.). Isozymes in Plant Genetics and Breeding: part A. Amsterdam: Elsevier Science, 1983. p.219-239.

BURDON, J.J.; MARSHALL, D.R. The use of isozymes research. In: TANKSLEY, S.D.; ORTON, T.J. (Ed.). Isosymes in plants genetics and breeding: part A. Amsterdam: Elsevier Science, 1983. p.401-412.

CHEN, J.; WANG, Z.; HONG, J.; COLLIER, C.R.; ADAMS, M.J. Ultrastructural studies of resting spore development in Polymyxa graminis. Mycological Research, v.102, p.687-691, 1998.

FERREIRA, M.E.; GRATTAPAGLIA, D. Introdução ao uso de marcadores moleculares em análise genética. 3.ed. Brasília: Embrapa-Cenargen, 1998. 220p.

GOTTLIEB, L.D. Conservation and duplications of isozymes in plants. Science, v.216, p.373-380, 1982.

HART, G. Hexaploid Wheat. In: TANKSLEY, S.D.; ORTON, T.J. (Ed.). Isozymes in plants genetics and breeding: part $\mathrm{B}$. Amsterdam: Elsevier Science, 1983. p.35-51.

McKINNEY, H.H.; ECKERSON, S.H.; WEBB, R.W. The intracelular bodies associated with the rosette disease and a mosaic like leaf mottling of wheat. Journal of Agricultural Research, v.26, p.605-608, 1923.

MELLON, J.E. Purification and characterization of isoperoxidases elicited by Aspergillus flavus in cotton ovule cultures. Plant Physiology, v.95, p.14-20, 1991.

PASCHOLATI, S.F.; DEISING, H.; LEITE, B.; ANDERSON, D.; NICHOLSON, R.L. Cutinase e non-specific esterase activities in the conidial mucilage of Colletotrichum graminicola. Physiological and Molecular Plant Pathology, v.42, p.37-51, 1993.

REUNIÃO DA COMISSÃO SUL-BRASILEIRA DE PESQUISA DE TRIGO, 35., 2003, Passo Fundo. Indicações técnicas da comissão sul-brasileira de pesquisa em trigo. Passo Fundo: Embrapa-CNPT; PF, 2003. p.48-49.

SCANDALIOS, J.G. Control of gene expression and enzyme differentiation. In: SCANDALIOS, J.G. Physiological genetics. New York: Academic Press, 1979. p.107.

SCANDALIOS, J.G. Genetic control of multiple forms of isozymes in plants: a review. Biochemical Genetics, v.3, p.37-79, 1969.

SILVA, E.A.A.; PINHO, E.V.R.V.; VIEIRA, M.G.G.C.; CARVALHO, M.L.M.; MACHADO, J.C. Alterações dos padrões de isoenzimas 
em sementes de milho infectadas com fungos. Pesquisa Agropecuária Brasileira, v.35, p.1725-1732, 2000.

TORGGLER, M.G.F.; CONTEL, E.P.B.; TORGGLER, S.P. Isoenzimas - variabilidade genética em plantas. Ribeirão Preto: Sociedade Brasileira de Genética. 1995. 87p.

VENERE, R.J. Role of peroxidase in cotton resistance to bacterial blight. Plant Science, v.20, p.47-56, 1980.

VISEDO, G.; FERNANDEZ-PIQUERAS, J.; GARCIA, J.A. Peroxidase isozyme analysis of factors involved in development of symptoms in Nicotiana clevelandii infected by Plum pox virus. Physiologia Plantarum, v.83, p.165-169, 1991.

WAGIH, E.E. Stress proteins and isozymes of acid phosphatase, esterase and peroxidase in Phaseolus vulgaris following localized virus infection. Assiut Journal of Agricultural Sciences, v.22, p.65-81, 1991.

YE, R.; ZHENG, T.; CHEN, J.; DIAO, A.; ADAMS, M. J.; YU, S.; ANTONIW, J.F. Characterization and partial sequence of a new Furovirus of wheat in China. Plant Pathology, v.48, p.379-387, 1990.

Recebido em 7 de julho de 2004 e aprovado em 7 de março de 2005 